Universidad de Lima

Facultad de Psicología

Carrera de Psicología

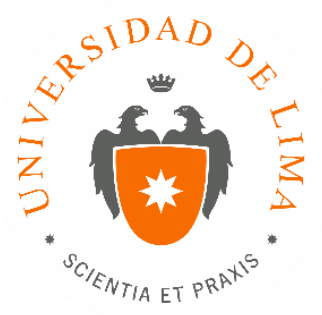

\title{
APLICACIÓN DE LA METODOLOGÍA REGGIO EMILIA EN EL PROCESO DE ENSEÑANZA - APRENDIZAJE DE NIÑOS DE 1 AÑO, 6 MESES A 2 AÑOS, 6 MESES DE UN CENTRO
EDUCATIVO DE NIVEL INICIAL
}

Trabajo de suficiencia profesional para optar el título profesional de Licenciado en Psicología

\author{
Andrea Patricia Santana Villafuerte
}

Código 20101038

Lima - Perú

Febrero de 2019 


\title{
APLICACIÓN DE LA METODOLOGÍA REGGIO EMILIA EN EL PROCESO DE ENSEÑANZA - APRENDIZAJE DE NIÑOS DE 1 AÑO, 6 MESES A 2 AÑOS, 6 MESES DE UN CENTRO EDUCATIVO DE NIVEL INICIAL
}

\author{
ÁREA EDUCATIVA
}




\section{TABLA DE CONTENIDO}

INTRODUCCIÓN. 7

CAPÍTULO I: IDENTIFICACIÓN DEL PROBLEMA...........................................

CAPÍTULO II: DESCRIPCIÓN DE LAS ACTIVIDADES REALIZADAS.......9

2.1 Diseño del periodo de adaptación...............................................................10

2.1.1 Orientado a los niños y niñas..................................................10

2.2.2 Orientado a los padres de familia...............................................11

2.2 Diseño de la prefiguración como punto de partida de la investigación........12

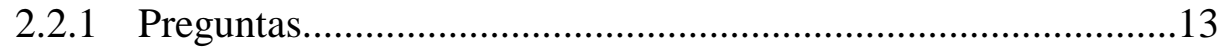

2.2.2 Hipótesis..............................................................................13

2.2.3 Justificación.............................................................................

2.2.4 Conceptos y Subconceptos........................................................14

2.2.5 Contextos de aprendizaje............................................................

2.3 Desarrollo del proyecto de investigación.....................................................15

2.3.1 Acompañamiento....................................................................16

2.3.1 Analizar e interpretar para sustentar la hipótesis.........................16

2.3.2 Dar visibilidad a la investigación.................................................17

2.4 Sistema de Evaluación por competencias.....................................................17

2.4.1 Cuadro de competencias........................................................17

2.4.2 Redacción de informe psicopedagógico........................................18

CAPÍTULO III: RESULTADOS DE LA INTERVENCIÓN...................................19

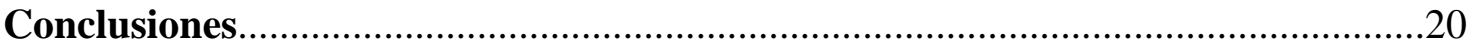

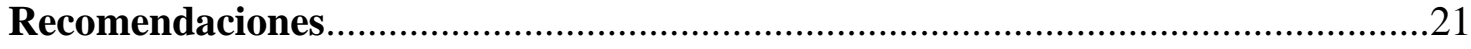

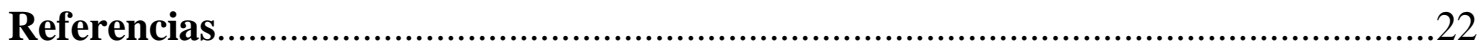

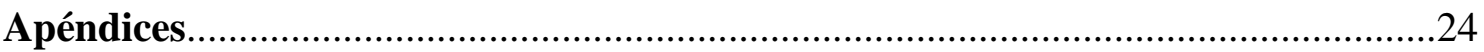




\section{ÍNDICE DE TABLAS}

Tabla 2.1: Conceptos principales y subconceptos a investigar....................................19 


\section{ÍNDICE DE APÉNDICES}

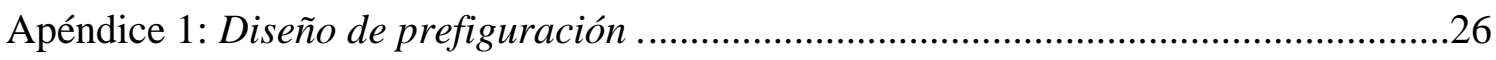

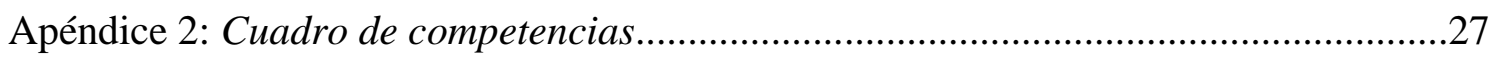

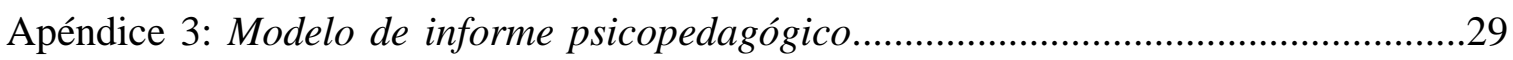




\section{INTRODUCCIÓN}

Las sociedades han avanzado y, por lo tanto, la educación necesita transformarse. Beltrán y Pérez (2011) mencionan que, dentro del contexto educativo, la psicología educativa ha logrado reconocer que el aprendizaje escolar implica un constante cambio y no una simple reproducción mecánica de respuestas; además, de identificar la secuencia de procesos mentales cognitivos y metacognitivos que el alumno tiene que emplear. Es así que la psicología educativa ha encontrado maneras adecuadas de adaptarse a las nuevas corrientes para cambiar el escenario de clase y convertirla en una comunidad que propicia el aprendizaje de conceptos reales; que estén conectados con la vida cotidiana de los estudiantes.

La ciudad italiana de Reggio Emilia es conocida mundialmente debido al nuevo enfoque que ha otorgado a la educación. Esta nueva mirada plantea que los niños tienen derecho a construir el aprendizaje y a desenvolverse en un ambiente en el que poseen libertad de acción (Martínez - Agut y Ramos, 2015). Loris Malaguzzi (como se citó en Hoyuelos, 2009), consideraba que los niños deberían ser vistos como portadores del conocimiento y con derecho a ser respetados y escuchados. Una concepción que va de la mano con la transformación que en la actualidad necesita la educación, dado que resulta importante adoptar nuevas propuestas que planteen mejores procesos pedagógicos y prácticas alternativas (Calvo, 2016).

Bajo este contexto, el reporte que se presenta detalla el ejercicio pre y profesional desempeñado en un centro educativo particular de nivel inicial y la forma en la que los conocimientos adquiridos durante los seis años de la carrera de Psicología resultaron fundamentales para lograr planificar y ejecutar el proceso de enseñanza-aprendizaje de niños con edades comprendidas entre 1 año, 6 meses y 2 años, 6 meses, utilizando la Filosofía Reggio Emilia como principal enfoque. 


\section{CAPÍTULO I: IDENTIFICACIÓN DEL PROBLEMA}

Las instituciones educativas del siglo XXI se están construyendo bajo la idea de que la escuela es un espacio que debe orientar su propuesta a formar alumnos que encajen y desarrollen habilidades para ser parte de una sociedad productiva. Por esta razón, no resulta sorprendente que al momento de pensar en la educación se aluda automáticamente al conjunto de contenidos prefijados, exámenes estandarizados, calificaciones, profesores que enseñan y niños que aprenden. Sin embargo, la educación va más allá de todo esto, pues Freire (2013) manifiesta que se debe romper con la idea de imponer una "educación bancaria", con la creencia de que el mejor docente es quien acumula mayor conocimiento en la mente de los alumnos y que estos solo cumplen un rol pasivo.

Esta idea de ruptura con lo tradicional se complementa con la propuesta educativa municipal italiana Reggio Emilia, cuya historia se remonta al año 1945 cuando apenas había finalizado la Segunda Guerra Mundial. Loris Malaguzzi, el creador de dicho enfoque, sintió la necesidad de reconstruir el territorio, empezando por la educación. De acuerdo con Hoyuelos (2009) se anhelaba implementar centros educativos de nivel inicial, donde los niños superen los traumas causados por la guerra y se cambie la imagen de un niño "tabla rasa", que aprende por reproducción, que solo almacena la información que le llega del exterior y que está determinado por su patrimonio genético.

Es así que, la construcción social que se debe buscar hoy en día para la escuela debería ser una que se sustente sobre el paradigma político y social de la democracia. Cox, Bascopé, Castillo, Miranda y Bonhomme (2014) mencionan que la democracia es un ideal y que la escuela tiene un rol protagónico para conseguirla; además, agregan que debe replantearse el currículo escolar para determinar acciones que impulsen su establecimiento y desarrollo. 
En el Perú se puede percibir una clara inconsistencia entre democracia, política y educación, pues en la práctica no se está llevando el proceso educativo bajo tales postulados, aunque La ley $N^{\circ} 28044$ (2017), Ley General de Educación, menciona dentro de sus principales principios a la ética, la democracia, la interculturalidad y la innovación

¿Cómo es posible construir una sociedad democrática si la escuela no promueve la creación y, más bien, trabaja sobre la estandarización del proceso de enseñanza-aprendizaje y promueve la homogeneidad en el pensamiento de los alumnos? Para que una sociedad se desarrolle necesita construir nuevas perspectivas, nuevos puntos de vista.

La filosofía Reggio Emilia, se crea para ser un lugar en el que se creen nuevas formas de convivencia, de conocimientos, un espacio en el que se vea a los niños como ciudadanos con una participación activa $\mathrm{y}$, sobre todo, como personas capaces de tomar decisiones. Las maestras, psicólogas y profesionales involucrados en la educación inicial están comprometidos con el objetivo de lograr que los niños desarrollen un vínculo especial con el aprendizaje a través de investigaciones interdisciplinarias e interacciones en las que sea posible representar ideas, construir significados propios y participar activamente dentro de la comunidad, para construir un fuerte sentido de pertenencia. 


\section{CAPÍTULO II: DESCRIPCIÓN DE LAS ACTIVIDADES}

\section{REALIZADAS}

Para iniciar la descripción que nombra este capítulo cabe mencionar que el cargo que el centro educativo asignó fue el de maestra-psicóloga y como labor principal la de liderar el equipo responsable de la planificación y ejecución del proceso de enseñanza-aprendizaje de los niños con edades comprendidas entre 1 año, 6 meses y 2 años, 6 meses. A continuación, se presentan las funciones que permitieron alcanzar el objetivo planteado para el puesto asignado.

\subsection{Diseño del periodo de adaptación}

Para asegurar que el proceso de enseñanza-aprendizaje se desarrollara exitosamente, se consideró primordial diseñar un periodo de adaptación orientado a los niños y padres de familia.

\subsubsection{Orientado a los niños y niñas}

En primer lugar, antes de iniciar las clases, se propuso implementar espacios dentro del aula que respondieran a la fase de desarrollo cognitivo en la que los niños se encontraban. Esta medida se consideró necesaria para asegurarles un espacio alineado con los intereses que, se pensaba, podrían poseer. Jean Piaget (1983) menciona que es la etapa sensorio-motriz, comprendida desde el nacimiento hasta los dos años, en la que los infantes buscan aprender por medio de las interacciones físicas con el entorno.

En segundo lugar, se determinó que los 17 niños y niñas que conformaban la clase asistieran durante las primeras semanas en grupos pequeños, por el espacio de una hora para dedicar el tiempo necesario y conocer las 
particularidades de cada uno. A partir de la tercera semana, el total de niños se dividió en dos grupos (uno de 8 y otro de 9), que asistió por un periodo de 2 horas. Esta dinámica generaba una mayor conciencia del entorno y que los lazos afectivos se extendieran. Ya en la cuarta semana, algunos asistieron con acompañante y otros solos. Los niños reconocían el espacio, a las maestras y a los compañeros.

En tercer lugar, al notar que los niños mostraban mayor disposición para compartir espacios, se destinó un momento del día para reunir a los niños y leer las denominadas "Cartas de identidad". Estas cartas las redactaron los padres de familia para detallar las características personales del niño o niña. El disfrute era evidente y transversalmente se aprovechó para desarrollar la atención sostenida, la comprensión y el lenguaje verbal.

\subsubsection{Orientado a los padres de familia}

Cuando el infante se incorpora a la dinámica escolar, experimenta un cúmulo de sentimientos, dada la separación de la figura de apego, esto significa un punto de partida para generar un conflicto entre el niño, el adulto y el entorno (Bowlby, 1985).

Sobre esta reflexión, se planteó agendar reuniones individuales antes de conocer a los niños, para dar la bienvenida a los padres de familia, obtener información sobre las expectativas e indagar sobre la dinámica familiar.

La cartilla de acompañamiento fue uno de los recursos principales empleados para apoyar a los padres durante el proceso de adaptación. Este documento detalla lo que se espera de ellos durante los primeros días y las conductas que deben mantener. Fue necesario, también, ofrecer información 
que les facilitara comprender la etapa que estaban experimentando ellos y sus hijos, por ello se les entregó material bibliográfico (libros, artículos de revistas e investigaciones) relacionado al área psicológica y pedagógica.

Durante las primeras semanas se dedicó un momento para registrar la forma en la que el adulto interactuaba con el niño, así como las estrategias que empleaba cuando se presentaba una situación de tensión. Sobre esto, y como maestra-psicóloga, se consideró oportuno intervenir cuando se percibía que algunas conductas del adulto necesitaban ser modificadas. Se aplicó conceptos basados en la disciplina positiva, una opción que mostró a los acompañantes una forma distinta para establecer normas de convivencia o pautas de crianza, y se les motivó a aplicarlas en ese instante. Jane Nelsen (2006) asegura que, para que los niños y niñas realmente logren ser personas reguladas $\mathrm{y}$ disciplinadas al relacionarse $\mathrm{y}$ aprender, es fundamental que cuenten con un escenario que les muestre la posibilidad de actuar autónomamente.

Se concluyó el periodo de adaptación con reuniones con los padres de familia para comunicar los logros alcanzados por sus niños y niñas. A partir de ese momento, se plantearon nuevos retos para que los alumnos desarrollasen nuevas competencias o se complejicen las obtenidas.

\subsection{Diseño de la prefiguración como punto de partida para la investigación}

La prefiguración fue la estrategia de planificación que se seleccionó y desarrolló para diseñar el proceso de enseñanza-aprendizaje. En ella se propone un conjunto de intenciones de acción que se toman para comprobar una hipótesis y las que ayudan a entender la forma en la que los niños y niñas aprenden. 
Ritchart, Church y Morrisson (2014) brindan soporte a esta herramienta de programación, pues manifiestan que, es fundamental tener claridad sobre qué tipos de actividad mental se está tratando de promover entre los alumnos, así como los caminos que se tomarán.

A continuación, se presentarán los pasos que se siguieron para llevar a cabo una de las prefiguraciones: "Conexiones que acogen, el propio descubrimiento como puente para establecer relaciones", estudió el juego de los niños y la forma cómo lo convierten en el recurso para establecer relaciones a todo nivel.

\subsubsection{Preguntas}

Lo primero que se tomó en cuenta para planificar la prefiguración fueron las preguntas: ¿Qué es lo que se desea entender? ¿Cuál se cree que es la problemática que se busca responder? Estas interrogantes sustentaron la motivación para llevar a cabo la investigación.

En el presente caso, se enfocó la mirada en estudiar los juegos que los niños entre el primer y segundo año de vida suelen realizar. Sobre esta observación surgieron las siguientes preguntas: ¿Cuáles son las características que identifican los juegos del grupo? ¿De qué manera estos juegos les permiten establecer relaciones? ¿Cuáles son las estrategias que emplean? ¿Cómo las descubren? ¿Será que estas experiencias los conectan con el medio con el que conviven y les permiten establecer relaciones?

\subsubsection{Hipótesis}

Se elaboraron posibles respuestas a las preguntas de investigación y como primera hipótesis se planteó que los juegos característicos de la etapa de 
desarrollo permiten a los niños establecer relaciones entre elementos, con el contexto y con las personas. Como segunda hipótesis se propuso que, a través de esos juegos, los niños logran por iniciativa propia descubrir y poner a prueba diversas habilidades (motrices, cognitivas, sociales, entre otras).

\subsubsection{Justificación}

Se realizó una búsqueda exhaustiva de material bibliográfico en plataformas virtuales, en la biblioteca del centro laboral y de la Universidad de Lima.

Por un lado, se encontró que a través del juego se tejen una serie de relaciones entre ideas y conceptos previos; los que, finalmente, al fusionarse con la información que recibe del entorno, le permiten modificar y establecer nuevas creencias que son el punto de partida para generar una mayor comprensión del medio (Piaget \& Inhelder, 1984).

Por otro lado, autores como Vygotsky (1979) conciben el juego como un instrumento y recurso socio cultural, ya que impulsa el desarrollo mental del niño y hace posible el desarrollo de sus funciones superiores.

Al surgir nuevas interrogantes, se consideró necesario recurrir nuevamente a fuentes bibliográficas.

\subsubsection{Conceptos y Subconceptos}

A partir del marco teórico se identificaron los conceptos principales y subconceptos a desarrollar durante la investigación. Estos se detallan desde el punto de vista que se estudiaron. Tal como se muestra en la Tabla 2.1 
Tabla 2.1

Conceptos principales y subconceptos a investigar.

\begin{tabular}{|l|l|}
\hline \multicolumn{1}{|c|}{ Conceptos } & \multicolumn{1}{|c|}{ Subconceptos } \\
\hline Relación & Interacción, conexión, vínculo. \\
\hline Adaptación & Etapa evolutiva, contexto, emoción. \\
\hline Secuencia de pensamiento & $\begin{array}{l}\text { Capacidades, destrezas, ensayo-error, creación de } \\
\text { conjeturas, construcción de significado. }\end{array}$ \\
\hline
\end{tabular}

\subsubsection{Contextos de aprendizaje}

Los contextos de aprendizaje son los espacios que se presentan dentro y fuera del aula designados para explorar los conceptos propuestos. Con la prefiguración en mano, se procedió a armar un mapa en el que se designó una ubicación específica para los materiales. Se crearon los contextos: "Juego Heurístico", "Construcción", "Naturaleza" y "Acogida”, que sirvieron para que los niños experimenten diversos tipos de juegos que necesitaban del empleo de diversas estrategias. Esta fue una forma de estudiar el juego desde distintas perspectivas.

La prefiguración muestra los pasos que se siguieron para lograr ejecutarla (ver apéndice 1)

\subsection{Desarrollo del proyecto de investigación}

Durante el desarrollo de los proyectos de investigación fue necesario recurrir a Carla Rinaldi (2006), asesora pedagógica de Reggio Children, ella apuesta porque los niños sean vistos como seres activos, competentes y fuertes, personas que averiguan y hallan significados y no como seres predeterminados, frágiles, necesitados e incapaces. Tener en mente dicha propuesta a lo largo de la investigación permitió recordar el compromiso que se debía mantener. 


\subsubsection{Acompañamiento.}

Se acompañó al grupo de niños en cada una de las exploraciones para tratar de comprender la intención de sus acciones, así como para prestar soporte y guiar cualquier situación en particular que pudiera presentarse.

En una de las etapas del desarrollo del proyecto de investigación surgió una problemática, se observó que algunos niños respondían y se conectaban con las propuestas de exploración, esto generaba que sus acciones sean cada vez más complejas. Sin embargo, otro grupo no mostraba curiosidad por explorar y cuando intentaban impactar sobre el material optaban por retirarse del espacio. Por lo tanto, se necesitó detenerse y analizar el contexto presentado, luego se concluyó que, posiblemente algunos niños habían logrado desarrollar competencias que otros compañeros todavía tenían en proceso. Se elaboró una tabla para registrar las acciones que cada niño realizaba durante la exploración y en diversos momentos del día, esto para identificar el nivel en el que se encontraban y luego proceder a diseñar estrategias que les permitieran alcanzar la Zona de Desarrollo Próximo.

La Zona de Desarrollo Próximo se refiere al nivel real de desarrollo determinado por la capacidad para resolver problemas de forma autónoma y al nivel de desarrollo potencial determinado a través de la resolución de un problema bajo la guía de un adulto o en colaboración con otro compañero (Vygotsky, 1979).

\subsubsection{Analizar e interpretar para sustentar la hipótesis.}

En esta fase, con medios audiovisuales (cámara de fotos, de video y grabadoras de voz), se registraron las intervenciones de los niños. Luego del 
horario de clase, por la tarde, se analizaba el material auditivo o audiovisual obtenido (que debía durar mínimo tres minutos) o la secuencia de fotos que reflejaban un proceso. Este análisis fue determinante para evaluar qué camino tomaba la investigación con relación a la hipótesis.

\subsubsection{Dar visibilidad a la investigación}

Durante el proceso del proyecto de investigación se creó una bitácora que presentaba las fotos, acciones y citas que habían surgido de los propios niños, así como las interpretaciones y reflexiones realizadas por las maestras y psicólogas. Todas las mañanas se promovía la lectura para conocer lo que el grupo estaba investigando.

Al finalizar el proyecto de investigación, se invitó a los padres de familia a la presentación final. Una presentación de PowerPoint, con fotos y videos, permitió exponer los diversos caminos que tomaron los niños para investigar los conceptos propuestos, así como las habilidades que desarrollaron y consolidaron. Además, se pudo precisar el valor pedagógico y psicológico en el desarrollo de estas acciones. Fue un momento para dialogar, reflexionar y otorgar valor a las intervenciones de los niños y una oportunidad para recordar que el centro educativo debe ser un espacio de creación de cultura e innovación.

\subsection{Sistema de Evaluación por Competencias}

\subsubsection{Cuadro de competencias.}

En la evaluación se elaboró un cuadro de competencias por bimestre (ver anexo 2) para reconocer los aprendizajes que se dieron durante el desarrollo de los proyectos de investigación y a lo largo de los distintos momentos del 
día. También para realizar una evaluación individual de la evolución de cada niño.

Recurrir al Programa Curricular de la Educación Inicial (2016) fue indispensable para determinar las competencias que el Ministerio de Educación define que se deben alcanzar en una edad determinada, y de acuerdo con las demandas que la sociedad actual exige poseer. Este programa constituyó una herramienta valiosa al momento de evaluar si el desarrollo evolutivo del niño se encontraba dentro de los parámetros esperados, así como para derivar determinados casos a un especialista de las áreas relacionadas al lenguaje, la terapia ocupacional, entre otras.

\subsubsection{Redacción de informes psicopedagógicos.}

Los informes psicopedagógicos redactados durante el tercer bimestre son informes cualitativos e informativos que reflejan las competencias que los niños han alcanzado durante el desarrollo de los proyectos de investigación y la rutina diaria. En ellos se tuvieron en cuenta los aspectos pedagógicos, relacionales y emocionales de los niños para tener una visión integral que permitiera entender la forma en la que lograron alcanzarlos (ver anexo 3).

Bajo esta premisa, se tomó el cuadro de competencias como guía para registrar las habilidades que los alumnos habían adquirido o las que se encontraban en proceso. Luego de registrar las competencias de cada niño, se consignaban en el informe escrito y se sustentaban con evidencia; es decir, se detalló la forma en la que se reflejaron en el centro educativo. Finalmente, se pactaron reuniones individuales con los padres de familia para comunicar los resultados. 


\section{CAPÍTULO III: RESULTADOS DE LA INTERVENCIÓN}

A partir de la sexta semana de iniciadas las clases se logró que los niños se despidan de sus acompañantes e ingresen solos al salón, además de permanecer tranquilos durante la jornada educativa. La forma en la que se evaluó dicho resultado contó con la intermediación de la coordinadora pedagógica, ella ingresaba constantemente al aula para llevar un registro de los niños que ya habían logrado el objetivo y de quiénes se encontraban en proceso. Durante esta observación se detenía para detallar la forma en la que los niños que ya habían logrado despedirse de sus acompañantes se desenvolvían durante el día, esto permitió identificar si realmente mantenían la serenidad.

Durante el año 2018, se desarrollaron tres proyectos de investigación. El primero, que se expone en el presente reporte, se realizó durante el primer y segundo bimestre; mientras que los dos siguientes se ejecutaron de forma paralela entre el tercer y cuarto bimestre. Los proyectos los evaluó la coordinadora y líder pedagógica antes de exponerlos a los padres de familia.

El 90\% de los padres de familia asistió a las exposiciones de los proyectos de investigación, lo que presentó una oportunidad para exponer los conceptos que los niños investigaron y fomentar el diálogo e intercambio de ideas. El diseño de un cuadro de control de asistencia permitió registrar el nivel de participación y compromiso de los padres de familia con la escuela a lo largo del año.

Los proyectos de investigación desarrollados fueron tomados por el centro educativo para la realización de capacitaciones dirigidas a diversos centros educativos interesados en implementar la filosofía Reggio Emilia. Asimismo, fue un material que aportó conocimiento y generó un espacio para intercambiar ideas entre los trabajadores del nido durante las reuniones de staff, realizadas por la tarde. 


\section{CONCLUSIONES}

- Contar con nociones básicas del desarrollo infantil y acudir a referentes que las sustenten resultó importante para desempeñar la labor asignada, así como tener en cuenta el diseño curricular que el Ministerio de Educación propone en la actualidad. Esto permitió una adecuada planificación de las estrategias de enseñanza - aprendizaje de acuerdo a las competencias que los niños necesitan desarrollar a una determinada edad.

- Ofrecer a los niños experiencias atractivas, acorde a su nivel de desarrollo ayudó a que reconozcan al centro educativo como un espacio que le brinda la seguridad necesaria para explorar. En este sentido las propuestas fueron un gran aliado para que surjan las primeras acciones, que serían el punto de partida para el desarrollo de los proyectos de investigación.

- El enfoque Reggio Emilia, muestra por qué cada vez más centros educativos desean implementarla, pues entiende la educación no como un resultado, por el contrario, como un proceso continuo y de reflexión en la que se deben planificar experiencias que permitan al niño reconocer que posee habilidades para asumir retos, para co - construir conocimiento, que sus intervenciones inspiran y son valoradas por el grupo.

- Lograr que más centros educativos de Perú implementen esta metodología sería una oportunidad para romper con en el enfoque tradicional. Propiciar una educación, cuyo proceso de enseñanza - aprendizaje se base en proyectos de investigación, permite estudiar los conceptos de manera contextualizada, así como analizarlos desde diversas perspectivas.

- Construir un fuerte sentido de comunidad no hubiera sido posible sin la participación de los padres de familia. Ellos, desde un inicio comprendieron que, acompañar a los niños durante el curso de su desarrollo era primordial. Los centros educativos deben considerar a los padres de familia, como uno de los principales agentes para poder trabajar en conjunto. 


\section{RECOMENDACIONES}

Luego de haber desempeñado la labor de maestra - psicóloga en un centro educativo de nivel inicial, se detallan las siguientes recomendaciones:

- Implementar un programa de inclusión, que permita a los niños con necesidades especiales obtener las mismas oportunidades de aprendizaje, basadas en el enfoque Reggio Emilia. A pesar que se implementaron diversas estrategias por parte de las maestras y psicólogas que lideraban la clase, hubiera sido pertinente contar con mayor apoyo y seguimiento por parte del departamento psicopedagógico.

- Tener en cuenta la cantidad de niños que conformarán las clases durante el año escolar. Esto con el fin de alcanzar, en el tiempo previsto, los objetivos planteados durante el proceso de la enseñanza - aprendizaje, así como otorgar el tiempo que le corresponde a cada niño para ser observado y escuchado. Contar con 17 niños en el aula recién adaptados, en algunas ocasiones generaba que se tenga que recurrir a la coordinadora pedagógica para que se incorpore al grupo y brinde apoyo para mantener la armonía.

- Organizar escuelas de padres en las cuales se invite a las familias para tratar temas que suelen presentarse con hijos de nivel inicial, pues en reiteradas ocasiones los padres de familia llegaban cada mañana con la intención de resolver dudas. Algunos casos podían ser atendidos en ese momento, pero otros debían ser agendados de acuerdo a disponibilidad.

- Replantear la cantidad de responsabilidades inmersas en el diseño del proceso de enseñanza - aprendizaje. En el presente reporte se presentan las acciones orientadas directamente a lograr ese objetivo; sin embargo, existen otras funciones que también debían ser desempeñadas de forma paralela. Las horas dentro de la jornada laboral no fueron suficientes para desarrollarlas. 


\section{REFERENCIAS}

Bowlby, J. (1985). La separación afectiva. Barcelona, España: Paidós.

Calvo, A. H. (2016). Viaje a la escuela del siglo XXI: Así trabajan los colegios más innovadores del mundo. Madrid, España: Fundación Telefónica.

Beltrán, L. J., y Pérez, S. L. (2011). Más de un siglo de psicología educativa. Valoración general y perspectivas de futuro. Papeles del Psicólogo, 32 (3), 204-231. Recuperado de: https://www.redalyc.org/articulo.oa?id=77822236002

Cox, C., Bascopé, M., Castillo, J. C., Miranda, D., y Bonhomme, M. (2014). Educación ciudadana en América Latina: Prioridades de los currículos escolares. IBE Working Papers on Curriculum Issues Recuperado de: http://repositorio.minedu.gob.pe/handle/123456789/4266

Freire, P. (2013). Pedagogia da esperança: um reencontro com a pedagogia do oprimido. Recuperado de: http://biblioteca.esec.pt/cdi/ebooks/docs/Pedagogia_da_Esperanca.pdf.

Hoyuelos, A. (2009). La ética en el pensamiento y obra pedagógica de Loris Malaguzzi. Barcelona, España: Octaedro.

Ley $\mathrm{N}^{\circ}$ 28044. (2017). Ley General de Educación. Lima, Perú. Recuperado de: http://www.minedu.gob.pe/p/ley_general_de_educacion_28044.pdf

Nelsen, J. (2006). Positive discipline. Canadá: Ballantine Books.

Piaget, J., e Inhelder, B. (1984). Psicología del niño. Madrid, España: Ediciones Morata

Piaget, J. (1983). Psicología de la inteligencia. Barcelona, España: Crítica.

Rinaldi, C. (2006). In dialogue with Reggio Emilia: Listening, researching and learning. Recuperado de: https://books.google.com.pe/books?id=i5FIPL1LEgkC\&printsec=frontcover\&hl=es\&s ource $=$ gbs_ge summary_r\&cad $=0 \# \mathrm{v}=$ onepage $\& \mathrm{q} \& \mathrm{f}=\mathrm{false}$ 
Martínez - Agut, M. P., y Ramos, H. C. (2015). Escuelas Reggio Emilia y los 100 lenguajes del niño: experiencia en la formación de educadores infantiles. In Actas del XVIII Coloquio de Historia de la Educación: Arte, Literatura y Educación, 2(3), 139-151. Recuperado de: https://dialnet.unirioja.es/servlet/articulo?codigo=5207311

Moss, P., Dahlberg, G., \& Pence, A. (2013). Beyond quality in early childhood education and care: Languages of evaluation. Recuperado de: https://books.google.com.pe/books/about/Beyond_Quality_in_Early_Childhood_Educa $\underline{\text { t.html} ? \mathrm{id}=\mathrm{t} \_\mathrm{h} 5 \mathrm{ZHBv} 85 \mathrm{kC} \& \text { redir_esc }=\mathrm{y}}$

Programa curricular de Educación inicial. (2016). Ministerio de Educación. Recuperado de: http://www.minedu.gob.pe/curriculo/pdf/programa-curricular-educacion-inicial.pdf

Ritchart, R., Church, M., y Morrison, K. (2014) Hacer visible el pensamiento. Cómo promover el compromiso, la comprensión y la autonomía en los estudiantes. Buenos Aires: Paidós.

Vygotsky, L. (1979). El desarrollo de los procesos psicológicos superiores. Barcelona, España: Crítica. 
APÉNDICES 


\section{APÉNDICE 1: DISEÑO DE PREFIGURACIÓN}

\begin{tabular}{|c|c|c|c|c|c|}
\hline \multicolumn{6}{|c|}{$\begin{array}{c}\text { CONEXIONES QUE ACOGEN EL PROPIO DESCUBRIMIENTO COMO PUENTE PARA ESTABLECER } \\
\text { RELACIONES }\end{array}$} \\
\hline Conceptos & Subconceptos & $\begin{array}{l}\text { Preguntas de } \\
\text { investigación }\end{array}$ & Hipótesis & Justificación & $\begin{array}{l}\text { Contextos de } \\
\text { aprendizaje }\end{array}$ \\
\hline Relación & $\begin{array}{l}\text { Interacción, } \\
\text { conexión, } \\
\text { vínculo. }\end{array}$ & $\begin{array}{l}\text { ¿Cuáles son las } \\
\text { características que } \\
\text { identifican los } \\
\text { juegos del grupo? }\end{array}$ & $\begin{array}{l}\text { Los juegos, } \\
\text { característicos } \\
\text { de la etapa de } \\
\text { desarrollo, } \\
\text { permiten a los } \\
\text { niños } \\
\text { establecer } \\
\text { relaciones } \\
\text { entre } \\
\text { elementos, con } \\
\text { el contexto y } \\
\text { con las } \\
\text { personas. }\end{array}$ & $\begin{array}{l}\text { Piaget e Inhelder, } \\
\text { (1984): Los dos } \\
\text { primeros años de } \\
\text { vida, se } \\
\text { caracterizan por la } \\
\text { interacción } \\
\text { constante que el } \\
\text { niño mantiene con } \\
\text { el medio, a través } \\
\text { del cual se teje } \\
\text { una serie de } \\
\text { relaciones entre } \\
\text { ideas y conceptos } \\
\text { previos que trae } \\
\text { consigo }\end{array}$ & $\begin{array}{l}\text { Juego } \\
\text { Heurístico: } \\
\text { elementos no } \\
\text { estructurados } \\
\text { reciclados }\end{array}$ \\
\hline Adaptación & $\begin{array}{l}\text { Etapa evolutiva, } \\
\text { contexto, } \\
\text { emoción. }\end{array}$ & $\begin{array}{l}\text { ¿De qué manera, } \\
\text { estos juegos, les } \\
\text { permite establecer } \\
\text { relaciones? }\end{array}$ & $\begin{array}{l}\text { A través del } \\
\text { juego los } \\
\text { niños logran, } \\
\text { por iniciativa } \\
\text { propia, } \\
\text { descubrir y } \\
\text { poner a prueba } \\
\text { diversas } \\
\text { habilidades } \\
\text { (motrices, } \\
\text { cognitivas, } \\
\text { sociales, entre } \\
\text { otras). }\end{array}$ & $\begin{array}{lr}\text { Vygotsky } & \text { (1979) } \\
\text { concibe el } & \text { juego } \\
\text { como } & \text { un } \\
\text { instrumento } & \text { y } \\
\text { recurso } & \text { socio } \\
\text { cultural, } & \text { pues } \\
\text { impulsa } & \text { el } \\
\text { desarrollo } & \text { mental } \\
\text { del } & \text { niño, } \\
\text { permitiendo } & \text { el } \\
\text { desarrollo de } & \text { las } \\
\text { funciones } & \\
\text { superiores } & \text { como } \\
\text { la atención } & \text { y la } \\
\text { memoria. } & \end{array}$ & $\begin{array}{l}\text { Naturaleza: } \\
\text { hojas, } \\
\text { semillas, } \\
\text { pepas, ramas, } \\
\text { recipientes, } \\
\text { cucharas, } \\
\text { linternas. }\end{array}$ \\
\hline \multirow[t]{2}{*}{$\begin{array}{l}\text { Secuencia de } \\
\text { pensamiento }\end{array}$} & $\begin{array}{l}\text { Capacidades, } \\
\text { destrezas, } \\
\text { ensayo y error, } \\
\text { creación de } \\
\text { conjeturas, } \\
\text { construcción de } \\
\text { significados. }\end{array}$ & $\begin{array}{l}\text { ¿Cuáles son las } \\
\text { estrategias que } \\
\text { emplean? ¿Cómo } \\
\text { las descubren? }\end{array}$ & & & $\begin{array}{l}\text { Construcción: } \\
\text { bloques, latas, } \\
\text { botellas. }\end{array}$ \\
\hline & & $\begin{array}{lr}\text { ¿Será que } & \text { estas } \\
\text { experiencias r los } \\
\text { conectan con el } \\
\text { medio ronde } \\
\text { conviven y les } \\
\text { permiten establecer } \\
\text { relaciones? }\end{array}$ & & & $\begin{array}{l}\text { Acogida: telas, } \\
\text { cajas, cuentos, } \\
\text { juegos } \\
\text { tranquilos. }\end{array}$ \\
\hline
\end{tabular}




\section{APÉNDICE 2: CUADRO DE COMPETENCIAS}

\begin{tabular}{|c|c|c|c|c|}
\hline & Bimestre 1 & Bimestre 2 & Bimestre 3 & Bimestre 4 \\
\hline \multirow{4}{*}{$\begin{array}{l}\text { Personal Social } \\
\text { Favorecer la } \\
\text { formación } \\
\text { personal y social } \\
\text { de los niños y } \\
\text { niñas } \\
\text { promoviendo y } \\
\text { acompañando } \\
\text { procesos como la } \\
\text { construcción de } \\
\text { su identidad a } \\
\text { partir } \\
\text { conocimiento y del } \\
\text { valoración de sí } \\
\text { mismos }\end{array}$} & $\begin{array}{l}\text { Responde a su } \\
\text { nombre }\end{array}$ & $\begin{array}{l}\text { Responde a su nombre } \\
\text { cuando se encuentra en } \\
\text { otro espacio }\end{array}$ & $\begin{array}{l}\text { Reconoce y llama } \\
\text { por su nombre a los } \\
\text { miembros del salón }\end{array}$ & $\begin{array}{l}\text { Responde a su } \\
\text { nombre y se } \\
\text { aproxima } \\
\text { cuando lo llaman }\end{array}$ \\
\hline & $\begin{array}{l}\text { Muestra interés } \\
\text { por participar en } \\
\text { sus cuidados } \\
\text { personales }\end{array}$ & $\begin{array}{l}\text { Participa en sus cuidados } \\
\text { personales por motivación } \\
\text { del adulto }\end{array}$ & $\begin{array}{lrr}\text { Participa } & \text { en } & \text { sus } \\
\text { cuidados } & \text { personales } \\
\text { desde su } & \text { propia } \\
\text { iniciativa } & y \\
\text { posibilidades } & \end{array}$ & $\begin{array}{l}\text { Sigue } \\
\text { indicaciones } \\
\text { simples en los } \\
\text { momentos de } \\
\text { cuidado }\end{array}$ \\
\hline & $\begin{array}{l}\text { Busca y acepta el } \\
\text { consuelo } \\
\text { compañía de su } \\
\text { adulto } \\
\text { significativo } \\
\text { cuando se siente } \\
\text { vulnerado } \\
\text { inseguro }\end{array}$ & $\begin{array}{l}\text { Experimenta y manipula } \\
\text { libremente diversos } \\
\text { medios y materiales para } \\
\text { descubrir sus propiedades }\end{array}$ & $\begin{array}{l}\text { Explora sus propias } \\
\text { ideas imaginativas } \\
\text { que construye a } \\
\text { partir de rus } \\
\text { vivencias }\end{array}$ & $\begin{array}{l}\text { Comparte } \\
\text { espontáneamente } \\
\text { sus experiencias } \\
\text { y creaciones }\end{array}$ \\
\hline & $\begin{array}{l}\text { Se identifica con } \\
\text { algunas de sus } \\
\text { características } \\
\text { físicas, sus } \\
\text { gustos, disgustos } \\
\text { e intereses con } \\
\text { ayuda del adulto }\end{array}$ & $\begin{array}{l}\text { Identifica a partir de } \\
\text { situaciones cotidianas y de } \\
\text { forma autónoma } \\
\text { determinadas partes de su } \\
\text { cuerpo }\end{array}$ & $\begin{array}{l}\text { Expresa } \\
\text { corporalmente } \\
\text { través del gesto, el } \\
\text { tono, las posturas y } \\
\text { movimientos sus } \\
\text { sensaciones } \\
\text { emociones } \\
\text { situaciones } \\
\text { cotidianas y recurre } \\
\text { al adulto cuando se } \\
\text { siente inseguro }\end{array}$ & $\begin{array}{l}\text { Se expresa } \\
\text { corporalmente } \\
\text { con sus pares } \\
\text { utilizando el } \\
\text { ritmo, gestos y } \\
\text { movimientos } \\
\text { como recursos } \\
\text { para comunicar }\end{array}$ \\
\hline \multirow[t]{4}{*}{$\begin{array}{l}\text { Psicomotriz } \\
\text { Se desenvuelve } \\
\text { de forma } \\
\text { autónoma a través } \\
\text { de su motricidad. }\end{array}$} & $\begin{array}{lr}\text { Explora } & \text { los } \\
\text { objetos de } & \text { su } \\
\text { entorno } & \text { y } \\
\text { reconoce r sus } \\
\text { características }\end{array}$ & $\begin{array}{lrr}\text { Clasifica } & \text { los } & \text { objetos de } \\
\text { acuerdo } & \text { a } & \text { distintos } \\
\text { patrones } & & \end{array}$ & $\begin{array}{l}\text { Establece relaciones } \\
\text { entre los objetos }\end{array}$ & $\begin{array}{l}\text { Traslada este } \\
\text { nuevo } \\
\text { conocimiento a } \\
\text { distintas } \\
\text { situaciones de la } \\
\text { cotidianidad }\end{array}$ \\
\hline & $\begin{array}{l}\text { Explora juegos de } \\
\text { continente- } \\
\text { contenido }\end{array}$ & $\begin{array}{l}\text { Reconoce el objeto como } \\
\text { un todo }\end{array}$ & $\begin{array}{l}\text { Reconoce las } \\
\text { características y } \\
\text { dimensiones del } \\
\text { objeto contenedor y } \\
\text { de los elementos } \\
\text { contenidos a través } \\
\text { del ensayo y error }\end{array}$ & $\begin{array}{l}\text { Discrimina } \\
\text { visualmente las } \\
\text { características y } \\
\text { dimensiones de } \\
\text { los objetos }\end{array}$ \\
\hline & $\begin{array}{l}\text { Se desplaza y } \\
\text { reconoce } \\
\text { progresivamente } \\
\text { su posición }\end{array}$ & $\begin{array}{l}\text { Reconoce la ubicación de } \\
\text { los objetos en el espacio }\end{array}$ & $\begin{array}{l}\text { Comprende algunas } \\
\text { expresiones sencillas } \\
\text { relacionadas a su } \\
\text { ubicación. "Me } \\
\text { parece que la vaca } \\
\text { está debajo de tu } \\
\text { pie" }\end{array}$ & $\begin{array}{l}\text { Comprende } \\
\text { expresiones } \\
\text { sencillas } \\
\text { relacionadas a la } \\
\text { ubicación de } \\
\text { objetos: "El } \\
\text { cojín está dentro } \\
\text { de la canasta" }\end{array}$ \\
\hline & $\begin{array}{l}\text { Explora nociones } \\
\text { de estabilidad y } \\
\text { equilibrio con su } \\
\text { cuerpo }\end{array}$ & $\begin{array}{l}\text { Explora nociones de } \\
\text { estabilidad y equilibrio } \\
\text { con objetos }\end{array}$ & $\begin{array}{lr}\text { Explora nociones de } \\
\text { estabilidad } & y \\
\text { equilibrio } & \text { con } \\
\text { características } & \\
\text { similares } & \end{array}$ & $\begin{array}{l}\text { Explora } \\
\text { nociones de } \\
\text { estabilidad y } \\
\text { equilibrio con } \\
\text { características } \\
\text { distintas }\end{array}$ \\
\hline
\end{tabular}




\begin{tabular}{|c|c|c|c|c|}
\hline $\begin{array}{l}\text { Comunicación } \\
\text { Se comunica } \\
\text { oralmente, } \\
\text { escucha lo que } \\
\text { otros le dicen, } \\
\text { pregunta } \\
\text { responde }\end{array}$ & $\begin{array}{l}\text { Se expresa } \\
\text { espontáneamente } \\
\text { a través del } \\
\text { lenguaje verbal } \\
\text { apoyándose en } \\
\text { gestos y lenguaje } \\
\text { corporal, con el } \\
\text { propósito de } \\
\text { interactuar con } \\
\text { otras personas de } \\
\text { su entorno }\end{array}$ & $\begin{array}{lr}\text { Se } & \text { expresa } \\
\text { espontáneamente a través } \\
\text { del lenguaje verbal } \\
\text { apoyándose en recursos } \\
\text { visuales que se encuentran } \\
\text { en el entorno }\end{array}$ & $\begin{array}{lr}\text { Mayor bagaje } & \text { de } \\
\text { vocabulario } & \mathrm{e} \\
\text { intención } & \\
\text { comunicativa } & \end{array}$ & $\begin{array}{l}\text { Emplea dos o } \\
\text { más palabras } \\
\text { para expresar sus } \\
\text { deseos, } \\
\text { necesidades y } \\
\text { relacionarse con } \\
\text { los demás }\end{array}$ \\
\hline & $\begin{array}{l}\text { Emplea señas, } \\
\text { gestos, sonrisas, } \\
\text { miradas, } \\
\text { movimientos } \\
\text { corporales y/o } \\
\text { algunas palabras } \\
\text { con la intención } \\
\text { de comunicarse o } \\
\text { lograr su } \\
\text { propósito }\end{array}$ & $\begin{array}{l}\text { Usa algunas palabras y } \\
\text { sonidos combinados que } \\
\text { se asemejan a palabras, así } \\
\text { comor movimientos } \\
\text { corporales, señas, gestos, } \\
\text { sonrisas y miradas con la } \\
\text { intención de comunicarse } \\
\text { o lograr su propósito }\end{array}$ & $\begin{array}{l}\text { Encuentran en los } \\
\text { juegos oportunidades } \\
\text { para expresarse } \\
\text { libremente }\end{array}$ & $\begin{array}{l}\text { Evocan } \\
\text { situaciones } \\
\text { intentan } \\
\text { narrarlas }\end{array}$ \\
\hline & $\begin{array}{lr}\text { Se interesa } & \text { por } \\
\text { cuentos } & \text { de } \\
\text { estructura } & \text { simple } \\
\text { en los que } & \text { qredominan las } \\
\text { predingen } & \end{array}$ & 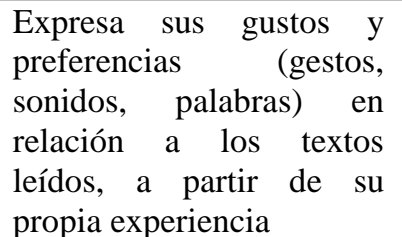 & $\begin{array}{l}\text { Demuestra } \\
\text { comprensión de las } \\
\text { ilustraciones que } \\
\text { transmiten } \\
\text { información }\end{array}$ & $\begin{array}{ll}\text { Sigue la } & \\
\text { secuencia de la } \\
\text { historia a lo } \\
\text { largo de la } \\
\text { narración }\end{array}$ \\
\hline $\begin{array}{lr}\text { Descubriendo el } \\
\text { mundo } \\
\text { Construcción de } \\
\text { sus propios } \\
\text { conocimientos a } \\
\text { partir de su deseo } \\
\text { por conocer y } \\
\text { comprender } \\
\text { mundo, y el } \\
\text { placer el } \\
\text { aprender }\end{array}$ & 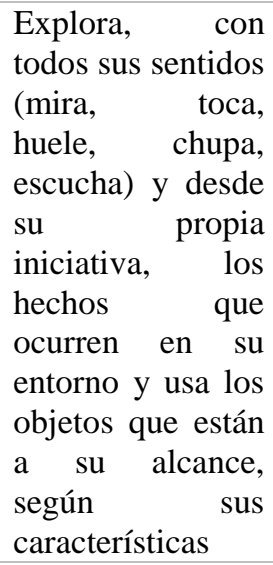 & $\begin{array}{l}\text { Convive y participa } \\
\text { cuando se relaciona con } \\
\text { otros niños y adultos en su } \\
\text { espacio cotidiano desde su } \\
\text { propia iniciativa y la de } \\
\text { los demás }\end{array}$ & $\begin{array}{l}\text { Complejiza } \\
\text { exploraciones a } \\
\text { partir de acciones } \\
\text { previas, personales o } \\
\text { colectivas }\end{array}$ & $\begin{array}{ll}\text { Creación } & \text { de } \\
\text { conjeturas, } & \\
\text { personales } & \text { o } \\
\text { colectivas } & \end{array}$ \\
\hline & $\begin{array}{lr}\text { Explora } & \text { los } \\
\text { materiales } & y \\
\text { conoce } & \text { la } \\
\text { ubicación } & \text { de } \\
\text { estos } & \end{array}$ & $\begin{array}{l}\text { Reconoce la funcionalidad } \\
\text { de los materiales }\end{array}$ & $\begin{array}{lcc}\text { Comprende } & \text { que los } \\
\text { materiales } & \text { y } & \text { los } \\
\text { espacios } & & \text { son } \\
\text { utilizados } & \text { por } & \text { los } \\
\text { demás } & & \end{array}$ & $\begin{array}{l}\text { Colabora en el } \\
\text { cuidado de los } \\
\text { materiales y de } \\
\text { los espacios } \\
\text { comunes }\end{array}$ \\
\hline & 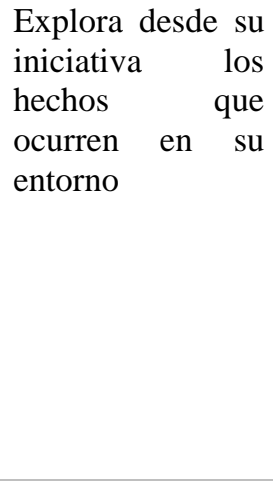 & $\begin{array}{l}\text { Establece diversas } \\
\text { relaciones entre los } \\
\text { elementos y herramientas } \\
\text { de exploración. } \\
\text { Ejemplo: "Un niño puede } \\
\text { emplear la linterna para } \\
\text { iluminar un elemento y } \\
\text { observar sus } \\
\text { características, pero } \\
\text { también puede emplearla } \\
\text { para proyectar una } \\
\text { sombra" }\end{array}$ & $\begin{array}{l}\text { Reconoce el impacto } \\
\text { que poseen sus } \\
\text { acciones sobre los } \\
\text { distintos elementos }\end{array}$ & $\begin{array}{l}\text { Se construye una } \\
\text { mirada sensible } \\
\text { hacia el medio } \\
\text { ambiente }\end{array}$ \\
\hline $\begin{array}{l}\text { Competencias } \\
\text { Transversales }\end{array}$ & \multicolumn{4}{|c|}{$\begin{array}{l}\text { Toma de decisiones - Autonomía - Observación a detalle - Cuidado del ambiente - Sentido } \\
\text { de pertenencia - Empatía - Relaciones interpersonales - Pensamiento creativo }\end{array}$} \\
\hline
\end{tabular}




\section{APÉNDICE 3: MODELO DE INFORME PSICOPEDAGÓGICO}

\section{INFORME PSICOPEDAGÓGICO}

Segundo Semestre, 2018

\section{Niño: I.C}

Resaltamos en I.C su mayor intención comunicativa y expansión de vocabulario para expresar y trasmitir sus ideas, deseos y necesidades. Además, su constante iniciativa por colaborar en los distintos momentos de la cotidianidad abre la posibilidad de fortalecer su sentido de pertenencia al grupo.

Celebramos la actitud investigadora de Ignacio para involucrarse y conectarse con las distintas propuestas de los contextos de investigación.

\section{Participación grupal}

Otorgamos valor a las relaciones que los niños establecen entre ellos y con los miembros de la comunidad. Es a través de esta participación activa que logran dar origen a diversas historias que se convierten en el puente para entablar, desarrollar y fortalecer vínculos.

Propone actividades y permite que sus compañeros y maestras formen parte de las mismas

Cada mañana, I.C llega en compañía de mamá. Disfrutan de pasar un momento juntos, para compartir la lectura de un cuento, ver su álbum familiar o visitar el espacio de "Hogar". Son estas experiencias en las que I.C se encuentra con los amigos que, poco a poco, ingresan al nido y quienes, en algunas ocasiones, se interesan por incorporarse a su juego.

Minutos más tarde, I.C está listo para despedirse y, junto a E.M y L.V, simbolizar el momento de la comida. Se acerca al estante y selecciona los individuales para colocarlos sobre la mesa; luego, busca algunos platos y los ubica, uno por uno, sobre cada individual, realizando así, un juego de correspondencia. Resaltamos la habilidad de I.C para reconocer la secuencia de pasos necesarias para este momento y cómo el proceso crea una estructura para él.

E.M y L.V se emocionan al ver la propuesta de I.C y muestran iniciativa por involucrarse. Ellos llevan a la mesa algunos alimentos como cereal, galletas y limones. Parece que esta 
acción motiva a I.C a complementar la idea de sus compañeros y dice "Leche", a la vez que extiende sus brazos hacia arriba, para que la maestra le entregue la caja. Ya en la mesa, E.M, L.V e I.C disfrutan de un intercambio de ideas y diálogos que hacen evidente la calidez con la que se escuchan y comparten.

"Uga verde" (lechuga verde) expresa I.C para llevar a la mesa este alimento, "Mmm" dice cuando acerca su nariz a los platos. Este momento finaliza al estar todos sentados en la mesa, allí las risas, miradas y gestos amables son las que prevalecen.

\section{Colabora con las responsabilidades de la clase}

Llevar la canasta de chuño y la toalla es una de las responsabilidades que a I.C le gusta realizar. La maestra le recuerda que ya es momento de buscarla en clase y lleno de emoción, abre la puerta, identifica el lugar donde se guarda y la obtiene. Con la canción "A limpiar los pies" I.C se dirige al patio. Allí, reconoce el lugar en el que debe acomodar los implementos y dice “Aquí, aqui'. Con ayuda de la maestra extiende la toalla y se preocupa porque sus amigos se acerquen. En algunas ocasiones acompaña a la maestra a cantar una canción y, en otras, busca a sus compañeros y los toma de la mano para llevarlos al ritual de limpieza.

Luego de comer la lonchera, invitamos a I.C a guardar los utensilios que usó. Él reconoce un patrón para organizarlos; a un lado apila los vasos y a otro lado los tazones. Se traslada con cuidado y se esfuerza por mantener el orden del espacio. Él suele ser, también, el responsable de limpiar la mesa cuando percibe que queda algún líquido o comida. "Mira, mira" nos dice para mostrarnos aquello que falta limpiar. Toma un paño de tela y con movimientos rápidos o lentos, a modo de juego, se motiva a dejar la mesa lista para el siguiente grupo. A través de esta experiencia, I.C comprende la importancia de su participación dentro del grupo.

Otorgamos valor a su presencia y reafirmamos nuestra confianza en sus capacidades, esto le permite alcanzar mayor autonomía y seguridad. Desde los primeros días, I.C o se caracterizó por mostrarse siempre dispuesto a compartir y explorar los distintos momentos de la cotidianidad en compañía de maestras y compañeros.

\section{Cuidados}

Los cuidados son parte esencial de nuestro trabajo. A través de ellos promovemos en los 
niños y niñas el desarrollo de su autonomía, el cariño, el respeto de sus tiempos, la actitud de escucha y la conciencia sobre su propio cuerpo.

Participa de manera autónoma en la alimentación

I.C seleccionó desde el principio la silla en la que deseaba sentarse y la mantiene hasta ahora, cada vez que ingresa al comedor se dirige directamente allí.

I.C muestra curiosidad por descubrir lo que comerá a través del sentido del olfato; es por eso que, cada vez que la maestra presenta el tazón de comida, aproxima su rostro y aspira hasta percibir el olor que le permite generar una atmósfera de sensaciones. Este primer momento es fundamental para que I.C despierte su interés y curiosidad por probar nuevos sabores.

I.C ha conseguido manipular la cuchara con mayor precisión frente a distintos tipos de alimentos $\mathrm{y}$, aunque a veces la textura de éstos dificulta su acción, emplea distintas estrategias como acomodar la comida sobre la cuchara con una de sus manos o comer directamente con ambas.

Continuamos trabajando en la espera de turnos y la importancia de permanecer sentados para ingerir los alimentos. "Má agua" (más agua) expresa a la vez que acerca el vaso a la maestra o pide "Mandaina" (mandarina) que es la fruta que, por ahora, es su preferida.

Otro momento que refleja la autonomía de I.C durante el "momento de la lonchera" se presenta cuando lo invitamos a pelar las frutas. La maestra inicia solo con una parte del plátano y ofrece la oportunidad a I.C para continuar con la acción. Él acomoda sus dedos y descubre que debe jalar con fuerza la cáscara y colocar la fruta en el tazón. Además, nos muestra su determinación y perseverancia para finalizar y conseguir pelar la fruta por completo.

\section{Colabora con la higiene de su propio cuerpo}

Durante el "momento del patio", cada vez que I.C desea ingresar al arenero reconoce que debe guardar sus zapatos y medias adentro de la java. Se acerca a la maestra y dice "Pato" (zapato) para solicitar su ayuda. En este momento lo motivamos a encontrar la estrategia precisa para cumplir su propósito.

I.C disfruta sentir distintas texturas y sensaciones con los pies. Cuando se le anticipa que está por llegar el momento de su limpieza comprende el mensaje, e inmediatamente se dirige a la java e identifica sus medias y zapatos para llevarlos a la alfombra donde realizamos este ritual. Pide el frasco de chuño diciendo "Uño uño", vierte el contenido y con suaves masajes retira la arena de sus dedos. 
Aunque algunas veces debemos recordar la importancia de permanecer sentados hasta finalizar la secuencia de pasos, Ignacio muestra iniciativa por colaborar e involucrarse en el cuidado de su propio cuerpo.

Registramos esta capacidad, también, durante el cambio de pañal. La maestra se acerca a I.C para decirle que pronto ingresará al baño. Él la toma de la mano y juntos inician este momento. I.C se sostiene de la baranda de la escalera del cambiador y sube hasta llegar a la colchoneta. Acá reconoce que debe regular sus movimientos para acomodarse y recostarse.

Este encuentro íntimo permite que I.C mantenga un diálogo con la maestra a través de palabras como "mamá, papá", los recuerda y desea que la conversación gire en torno a ellos. Aprovechamos, también, este momento especial y de conexión para generar una mayor conciencia de su propio cuerpo. Mencionamos los ojos, la boca, la barriga y demás partes para que Ignacio las reconozca y relacione.

Proponemos este tipo de experiencias para que I.C se conecte con su propio cuerpo y con las posibilidades que le ofrece, para continuar desarrollando competencias que le permitan desenvolverse en los distintos momentos de la cotidianidad.

\section{Pensamiento lógico matemático/literacidad-gráfica}

El pensamiento lógico matemático permite al niño organizar los objetos y los acontecimientos de su mundo. A través de estas interacciones logra establecer relaciones, clasificar, seriar, contar, medir, ordenar y aprender las operaciones lógico-matemáticas. Por otro lado, la literacidad y la gráfica son un aprendizaje básico para todo ser humano, ya que permiten transmitir, intercambiar ideas, expresar lo que sentimos o comunicarnos.

\section{Explora nociones de estabilidad y equilibrio de los elementos y con su propio cuerpo.}

En estas últimas semanas, montar el triciclo se ha convertido en uno de los juegos preferidos de I.C. Para sentarse, notamos las distintas posiciones que requiere adoptar su cuerpo y el control que debe tener en sus movimientos. Arrodillarse sobre el asiento y luego abrir sus piernas es la estrategia que ha seleccionado y con la que siente mayor confianza. Cuando, necesita de mayor estabilidad opta por extender sus brazos hacia los lados para no caer y mantenerse sentado. Coloca los pies sobre los pedales, pero parece sentirse más cómodo apoyándolos sobre el piso para impulsarse mejor y lograr avanzar.

Si I.C encuentra algunos obstáculos que interrumpen su recorrido baja del triciclo y lo 
empuja para, luego, volver a subir y continuar manejando. Luego le cede el turno a Antonia y corre detrás de ella mientras maneja. Antonia se detiene e Ignacio aprovecha para sentarse con ella, la abraza y juntos montan el triciclo.

I.C también muestra iniciativa para involucrarse en juegos que permiten elaborar estructuras verticales. Él agrupa los bloques de acuerdo a su forma y los apila hasta que formen una construcción con altura significativa. I.C, a través del ensayo-error, reconoce que debe apoyar primero los bloques más grandes y finalizar con los pequeños para conseguir mayor estabilidad. A medida que agrega más bloques, reconoce que debe hacer movimientos suaves para evitar que la construcción se derrumbe. Esta es una manera lúdica de aproximarse a conceptos matemáticos de cantidad. Expresa "más" cuando desea alcanzar mayor altura y requiere agregar bloques.

\section{Mayor bagaje de vocabulario e intención comunicativa}

En el "momento de relajación" ha surgido un nuevo juego: nombrar los colores de los zapatos. Nos sentamos en un círculo e invitamos a los niños a extender sus piernas. La maestra dice: "Zapato, zapato..." e Ignacio responde: “Verde, azul, rojo...”, esta acción permite e incentiva la conexión con la propuesta.

El mayor desarrollo de su vocabulario le ha abierto la posibilidad de involucrarse y tener más participación en el grupo. Ignacio también es capaz de leer su álbum familiar a algunos compañeros. Dice: “Mira mira” cuando desea que vean sus fotos y nos cuenta que personas o elementos especiales aparecen.

Esta es una oportunidad para fortalecer sus vínculos y para reconocer que su voz también es importante. Esta explosión léxica ha permitido que I.C encuentre mayores recursos para comunicarse, así como la iniciativa por ampliar su vocabulario.

La canción de "Bartolito" es una de las que más disfruta cantar. I.C representa, a través de sonidos, aquellos animales que la maestra nombra, esto refleja su habilidad para asociar y relacionar partiendo de consignas verbales. Expresa: "Pío pio, oink, cuac" y cuando la maestra pregunta: “¿Ese es Bartolito?”, I.C dice: “Nooo” (acompañado de un gesto con la mano). Cuando desea que la maestra entone una determinada canción dice: "Vaca vaca", que hace referencia a la canción de la "Vaca Lola", si dice "Ujita" se refiere a la canción "La brujita". 
Los distintos escenarios propuestos a los niños los invita a desarrollar espontáneamente las distintas áreas del lenguaje, cognitiva, social, matemática, etcétera. Es así que buscamos ofrecerles experiencias retadoras que se ajusten a sus necesidades y zona de desarrollo próximo. A lo largo de los diversos momentos de la cotidianidad les ofrecemos la oportunidad de sumergirse en el mundo de la matemática y de la literacidad de una manera lúdica. 